\title{
A Socio-demographic Survey on Infertile Couples of Selected Villages in Dhaka
}

\author{
Ali $\mathrm{M}^{1}$, Ahmad $\mathrm{M}^{2}$, Haque $\mathrm{MM}^{3}$, Airin $\mathrm{J}^{4}$
}

\begin{abstract}
Introduction: Infertility is a public health issue; it is defined as not having conceived after one year of unprotected sexual intercourse. In developing countries, there are severe social, psychological and economic consequences for infertile men and women.
\end{abstract}

Objectives: This study was designed to find out socio-demographic attributes and treatment seeking pattern about the infertile couple (either of the couple).

Materials and Methods: This survey was carried out in some selected villages of Ashulia, Saturia and Baliati of Dhamrai Upazilla in Dhaka. A total of 52 couples were included in the study. Purposive sampling technique was adopted. Couple who gave consent to participate in the study was interviewed. A structured questionnaire was used to collect the relevant information. Data were analyzed later on.

Results: Among husbands $18(34.6 \%)$ were between age $40-49$ years, $16(30.8 \%)$ were in the age group 30-39 years, $14(26.9 \%)$ were in the age group 20-29 years. Regarding age of the wives, majority, $32(61.5 \%)$ were in the age group $20-29$ years, $14(26.9 \%)$ had age $30-39$ years and rest $6(11.6 \%)$ were in the age group 40-49 years. About education of the husbands it was seen that $20(38.5 \%)$ passed SSC, $14(26.9 \%)$ had education from class $\mathrm{VI}$ to class $X$ and $6(11.5 \%)$ were illiterates. Among wives, $32(61.4 \%)$ had education on class $\mathrm{VI}$ to class $\mathrm{X}$, $10(19.2 \%)$ had primary level of education, $4(7.7 \%)$ were illiterates. Thirty four (65.4\%) couples lived in nuclear families, $16(30.8 \%)$ were joint families and the rest $2(3.8 \%)$ were extended families. Twenty eight $(53.8 \%)$ of the couples had marital life $>10$ years, $20(38.5 \%)$ had $6-10$ years and the rest $4(7.7 \%)$ had marital life of $1-5$ years. About $16(31 \%)$ had monthly income 5001-10000 taka, 10(19.2\%) had 15001-20000 taka, another 10(19.2\% had $>20000$ taka, 16(30.8\%) had 5001-10000 taka and $2(3.8 \%)$ had monthly income upto 5000 taka. Twenty $(38 \%)$ husband were involved in business and $44(76 \%)$ wives are house wives. Thirty two $(61.5 \%)$ couple used contraceptives. Forty two (80.8/\%) couples sought for treatment.

Conclusion: In developing countries, Infertility has profound effects on individuals as the production of children is often highly socially valued and is vital for social security and for family income generation. National level active planning is needed to overcome this social problem.

Key-words: Infertile couples, contraceptive.

\section{Introduction}

Infertility is the inability to conceive or carry a pregnancy to term after 12 months of trying to conceive. When a woman is unable to ever bear a child, either due to the inability to become pregnant or the inability to carry a pregnancy to a live birth she would be classified as having primary infertility. Primary infertility is also defined as the absence of a live birth for a woman who desire a child and have been in a union with her husband for at least five years during which they have not used any contraceptives ${ }^{1}$. The World Health Organization also adds that 'women whose pregnancy spontaneously miscarries or whose pregnancy results in a still born child, without ever having had a live birth would present with primarily infertility ${ }^{2}$. There are many biological and other causes of infertility, including

1. Brig Gen Mohammad Ali, MBBS, DPH, MPhil(PSM), Professor and Head, Department of Community Medicine, AFMC, Dhaka; 2. Lt Col Mushtaq Ahmad, MBBS, DFM, MCPS, FRSPH, Associate Professor and Head, Dept of Forensic Medicine, AFMC, Dhaka 3. Dr. Md Mahmudul Haque, Associate Professor of Community Medicine, NIPSOM, Dhaka; 4. Dr. Jinnatul Airin, MBBS, MPH(RCH), Lecturer, Department of Community Medicine, AFMC, Dhaka. 
some that medical intervention can treat ${ }^{3}$. Infertility rates have increased by $4 \%$ since the 1980 s, mostly from problems with fecundity due to an increase in age $^{4}$. About $40 \%$ of the issues involved with infertility are due to the man, another $40 \%$ due to the woman, and $20 \%$ result from complications with both partners and unknown causes ${ }^{5,6}$

Some estimates suggest that worldwide "between three and seven per cent of all couples or women have an unresolved problem of infertility. Many more couples, (estimates range from $12 \%$ to $28 \%$ ) however, experience involuntary childlessness for at least one year ${ }^{7}$. The medicalization of infertility has unwittingly led to a disregard for the emotional responses that couples experience, which include distress, loss of control, stigmatization, and a disruption in the developmental trajectory of adulthood $^{8}$. More than hundred million couples are estimated to be infertile worldwide. In our society, where people are affected by superstitious belief, wives are mostly blamed though husbands as responsible ${ }^{9}$. This study was designed to find out socio-demographic attributes about the infertile couple (either of the couple) and have some information regarding their treatment seeking pattern.

\section{Materials and Methods}

This survey was carried out in some selected villages of Ashulia, Saturia and Baliati of Dhamrai Upazilla in Dhaka. A total of 52 couples were included in the study. This is cross sectional study and Purposive sampling technique was adopted. Couple who gave consent to participate in the study was interviewed. A structured questionnaire was used to collect the relevant information. Data were analyzed later on.

\section{Results}

Table-I reveals that of the husbands $18(34.6 \%)$ had age $40-49$ years, $16(30.8 \%)$ were in the age group $30-39$ years, $14(26.9 \%)$ were in the age group 20-29 years and the rest $4(7.7 \%)$ had age $50-59$ years.

Table-I: Distribution of the couples by husbands' age.

\begin{tabular}{|l|c|c|}
\hline Age of the husbands & Frequency & Percentage \\
\hline $20-29$ years & 14 & 26.9 \\
\hline $30-39$ years & 16 & 30.8 \\
\hline $40-49$ years & 18 & 34.6 \\
\hline $50-59$ years & 4 & 7.7 \\
\hline Total & $\mathbf{5 2}$ & $\mathbf{1 0 0 . 0}$ \\
\hline
\end{tabular}

Regarding age of the wives it was seen that majority $(61.5 \%)$ were in the age group 20-29 years, 14 $(26.9 \%)$ had age $30-39$ years and rest $6(11.6 \%)$ were in the age group 40-49 years (Table-II).

Table-Il: Distribution of the couples by wives' age.

\begin{tabular}{|l|c|c|}
\hline Age of the wives & Frequency & Percentage \\
\hline $20-29$ years & 32 & 61.5 \\
\hline $30-39$ years & 14 & 26.9 \\
\hline $40-49$ years & 6 & 11.6 \\
\hline Total & $\mathbf{5 2}$ & $\mathbf{1 0 0 . 0}$ \\
\hline
\end{tabular}

About education of the husbands it was seen that 20 (38.5\%) passed SSC, 14(26.9\%) had education from class VI to class X, $6(11.5 \%)$ had HSC, $4(7.7 \%)$ were graduates and $6(11.5 \%)$ were illiterates (Fig-1).

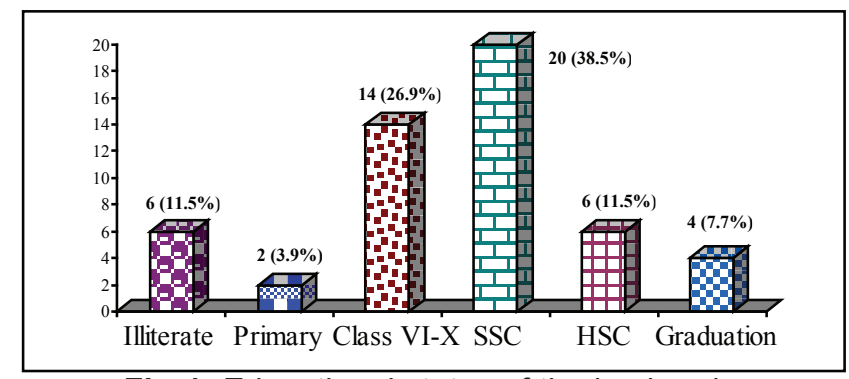

Fig-1: Educational status of the husbands.

Figure-2 shows education of the wives. Out of the total $52,32(61.4 \%)$ had education on class $\mathrm{VI}$ to class $\mathrm{X}, 10(19.2 \%)$ had primary level of education, $4(7.7 \%)$ had SSC, $2(3.9 \%)$ were graduates and 4 $(7.7 \%)$ were illiterates.

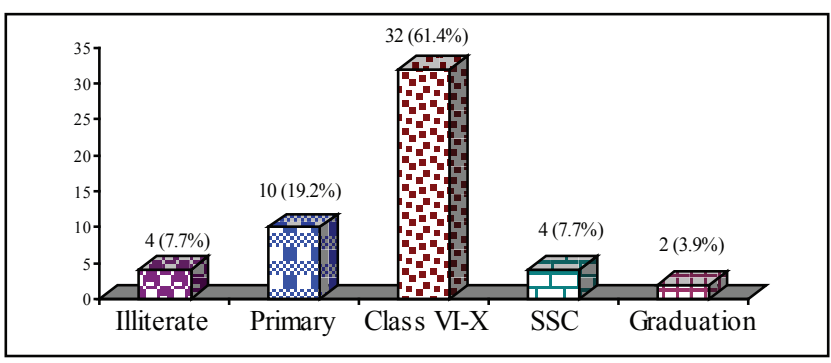

Fig-2: Educational status of the wives.

Out of the total 52 families, 34(65.4\%) were nuclear families, 16(30.8\%) were joint families and the rest 2 $(3.8 \%)$ were extended families (Fig-3).

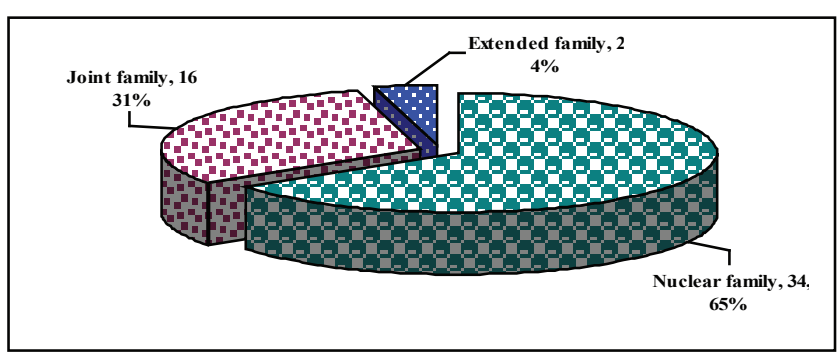

Fig-3: Family type of the couples. 
Table-III opines that $28(53.8 \%)$ of the couples had mantlal ife $>10$ years, $20(38.5 \%)$ had $0-10$ years

Table-III: Distribution of the couples by duration of

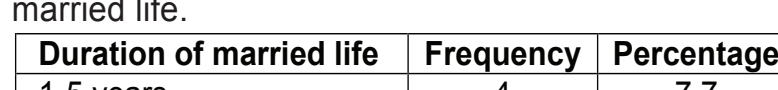
\begin{tabular}{|l|l|l|}
\hline $1-5$ years & 4 & 7.7 \\
\hline $6-10$ years & 20 & 38.5 \\
\hline$>10$ years & 28 & 53.8 \\
\hline
\end{tabular}

Monthly income of the respondent is shown in Table-IV. About $16(31 \%)$ had monthly incom another $10(19.2 \%$ had $>20000$ taka, $16(30.8 \%)$ had $5001-10000$ taka and $2(3.8 \%)$ had monthly income upto 5000 taka.

Table-IV: Distribution of the couples by duration of

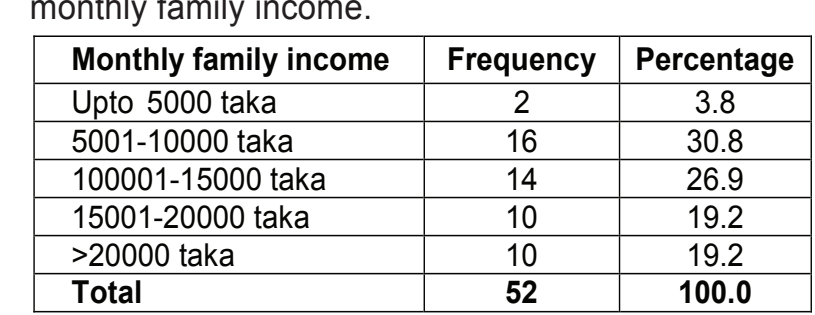

Regarding occupation of the husbands it was see that $20(38 \%$ ) were doing business, another $20(38 \%)$ agriculture and the rest $8(15 \%)$ were engaged in other occupations (Fig-4).

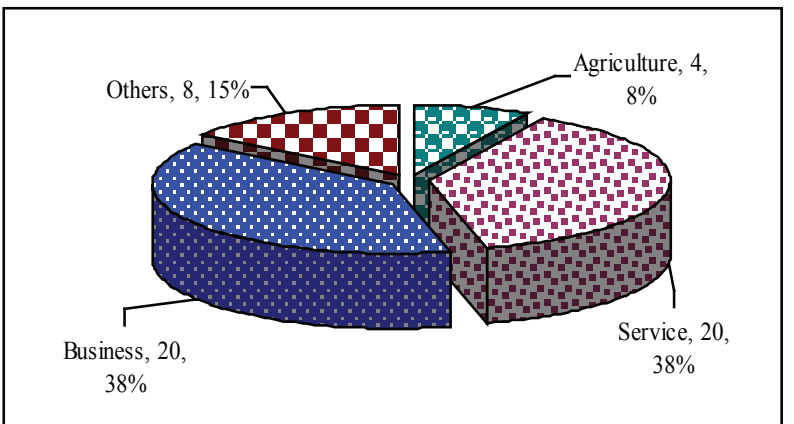

Fig-4: Distribution of the couples by husbands occupation.

Majority $[44(76 \%)]$ of the wives were housewives About $10 \%$ were doing service and the rest $8(14 \%)$ were in some other occupation (Fig-5).

AFFC Bangladesh. Vol 11, № 1 (June) 2015

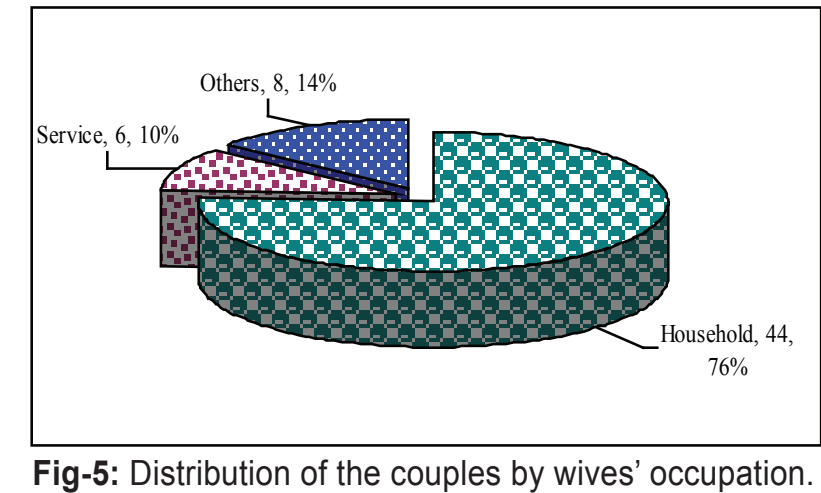

tribution of the couples by wives' occupation. Table-V reveals that $32(61.5 \%)$ couples used contraceptive ever. Among them majority (93.8\%) seen that $20(62.4 \%)$ used for $1-5$ years, $6(18.8 \%)$ used contraceptives for $6-10$ years and the rest of the users $(18.8 \%)$ used contraceptives for less than one year.

Table-V: Distribution of the couples by contraceptive use
Characteristics Frequency Percentage Ever used contraceptives $(\mathbf{n}=52)$ \begin{tabular}{|l|l|}
32 & 61.5 \\
\hline
\end{tabular}

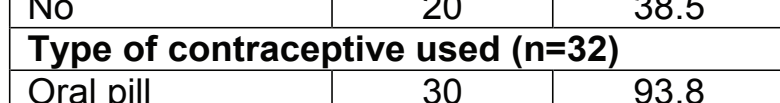
\begin{tabular}{|l|c|c|}
\hline Oral pill & 30 & 93.8 \\
\hline Safe period & 2 & 6.2 \\
\hline Dut
\end{tabular}

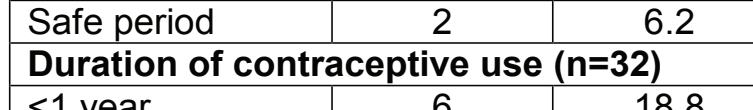
\begin{tabular}{|l|c|c|}
\hline 1 year & 6 & 18.8 \\
\hline $6-10$ years & 20 & 62.4 \\
\hline 6 & 6 & 18.8 \\
\hline
\end{tabular} The-VII shows that out of the 52 infertile couples, $42(80.8 \%)$ sought for treatment before. Amon these 42 couples, $20(47.6 \%)$ went to Govt hospitals $12(28.6 \%)$ went to NGO clinics and the res 8 couples did not seek treatment for inf familial non-co-operation and 2 couples for familia constraint. \begin{tabular}{l} 
Table-VI: Distribution of the couples by treatment sought for infertility \\
\begin{tabular}{|l|l|}
\hline Characteristics & Frequency \\
\hline Sought treatment for infertility (n $n=52)$ \\
\hline
\end{tabular} \\
\hline
\end{tabular} \begin{tabular}{|l|c|c|}
\hline Yes & 42 & 80.8 \\
\hline No & 10 & 19.2 \\
\hline Reasons behind not seeking treatment $(\mathbf{n}=10)$ \\
\hline
\end{tabular} \begin{tabular}{l|c|c|} 
& & \\
\end{tabular} \begin{tabular}{|l|l|}
\hline Familial constraint $\frac{2}{2}$ & 20.0 \\
\hline lace of seeking treatment $(n=42)$ &
\end{tabular} \begin{tabular}{|l|r|r|}
\hline Govt. hospital & 20 & 47.6 \\
\hline NGO & 12 & 28.6 \\
\hline Traditional healer & 10 & 238 \\
\hline
\end{tabular} 
Fig-6 reveals that all of the couples who sought treatment for infertility before (42) were asked to perform complete blood count (CBC), urine analysis and semen analysis. More than half $(52.4 \%)$ were advised ultra-sonogram (USG) and 18(43\%) were asked for blood biochemistry. Multiple responses exists (Fig-7)

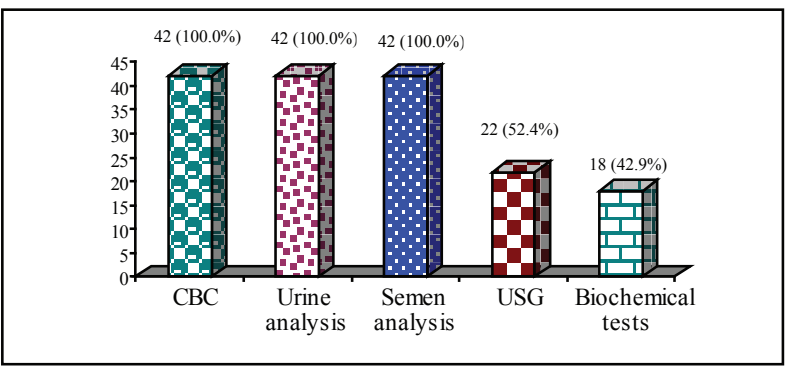

Fig-6: Distribution of the couples by investigation done for infertility $(n=42)$

Table-VII opines that majority of the couples [34 (65.4)] spent $>15000$ taka for treatment for inferily, $10(19.2 \%)$ spent upto10000 taka and $8(15.4 \%)$ spent 10001-15000 taka.

Table-VII: Distribution of the couples by money spent for infertility.

\begin{tabular}{|l|c|c|}
\hline Amount spent & Frequency & Percentage \\
\hline upto 10000 taka & 10 & 19.2 \\
\hline $10001-15000$ taka & 8 & 15.4 \\
\hline$>15000$ taka & 34 & 65.4 \\
\hline Total & $\mathbf{5 2}$ & $\mathbf{1 0 0 . 0}$ \\
\hline
\end{tabular}

Fig-7 shows that $40(76.9 \%)$ of the couple got support from their families and the rest $12(23.1 \%)$ did not get support from their families.

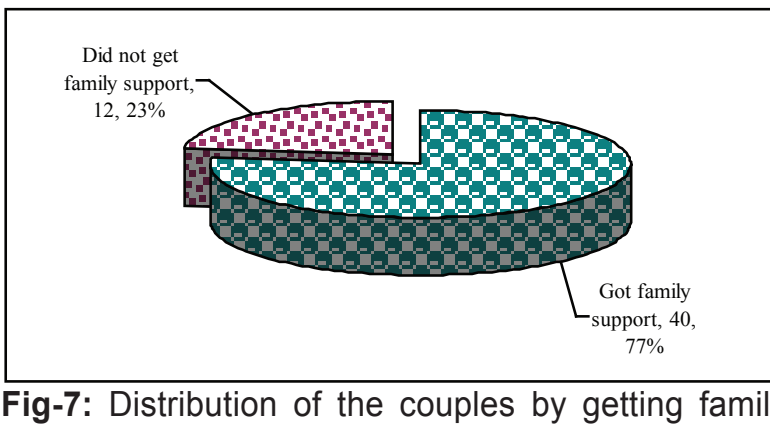

support for treatment of infertility.

\section{Discussion}

Infertility and sterility is a socio-medical problem. About three million couples in Bangladesh are infertile and number is increasing very first due to rapid changing in socio economic norm. The cross sectional study was conducted among 52 infertile couples to find some socio-demographic attributes about the infortile couple and have some information regarding their treatment seeking pattern. Of the husbands $18(34.6 \%)$ were between age $40-49$ years, $16(30.8 \%)$ were in the age group $30-39$ years and of the wives $32(61.5 \%)$ were in the age group $20-29$ years and $14(26.9 \%)$ had age $30-39$ years.

Among the husbands $88.5 \%$ were literate and among wives $92.3 \%$ were literates. In Bangladesh the literacy rate is $78.56 \%$. Finding of this study are consistent with the national figure. Studies have shown that the relationship between female education and fertility is found to be negative in less developed countries ${ }^{10}$. In another study Wright et al ${ }^{11}$ (1988) reported that education has no net effect on fertility rate. However birth rate could be brought down by enhancing female empowerment through increasing levels of female education and birth control procedure, which is not applicable for infertile couples ${ }^{12}$.

Out of the total 52 families, $34(65.4 \%)$ were nuclea families, $16(30.8 \%)$ were joint families and the rest 2 $(3.8 \%)$ were extended families. More than half $(53.8 \%)$ of the couples had marital life $>10$ years, 20 $(38.5 \%)$ had $6-10$ years and the rest $4(7.7 \%)$ had marital life of $1-5$ years. About $31 \%$ had monthly income 5001-10000 taka. Regarding occupation of the husbands it was seen that $20(38 \%)$ were doing business, another $20(38 \%)$ were service holders. Majority $(76 \%)$ of the wives were housewives.

Majority $(61.5 \%)$ used contraceptive at any time. Among them majority (93.8\%) used oral pills. In another study performed by Akhter (2008) among 173 women showed $87.8 \%$ used different method of contraception; $79.76 \%$ women used modern method and $20.2 \%$ women used natural method. Thirty three percent couple practiced barrier method, $22.5 \%$ percent use oral pill ${ }^{13}$.

Out of the 52 infertile couple $42(80.8 \%)$ sought for treatment before. Among these 42, 20(47.6\%) went to Govt. hospitals, $12(28.6 \%)$ went to NGO clinics and the rest $10(23.8 \%)$ went to traditional healers. All of the couples who sought treatment for infertility before (42) were asked to perform complete blood 
count $(\mathrm{CBC})$, urine analysis and semen analysis. More than half $(52.4 \%)$ were advised ultrasonogram (USG) and 18(43\%) were asked for blood biochemistry. Among the 52 couples 40(76.9\%) got support from their families and the rest $12(23.1 \%)$ did not get support from their families. Other researchers found that couples experience stigma, sense of loss, and diminished self-esteem in the setting of their infertility. It is seen in general, in infertile couples women show higher levels of distress than their male partners ${ }^{14}$. A number of studies have found that the incidence of depression in infertile couples presenting for infertility treatment is significantly higher than infertile couples. Anxiety has also been shown to be significantly higher in infertile couples when compared to the general population $^{15}$. Infertile women have more mental health problems than fertile women ${ }^{16-19}$.

\section{Conclusion}

Infertility has profound effects on individuals in developing countries, as the production of children is often socially highly valued and vital for social security and health networks as well as for family income generation. Infertility in these societies often leads to social stigmatization and abandonment by spouses. Advances in assisted reproductive technologies, such as In Vitro Fertilization (IVF) can offer hope to many couples where treatment is available, although barriers exist in terms of medical coverage and affordability. National level active planning is needed to overcome this social problem.

\section{References}

01. Sexual and reproductive Health. [cited 2015 January 12] Available from: http://www.who.int/ reproductive health/ topics/infertility/definitions/en/

02. Cousineau TM, Domar AD. "Psychological impact of infertility". Best Pract Res Clin Obstet Gynaecol 2007; 21 (2): 293-308.

03. Makar RS, Toth TL. "The evaluation of infertility". Am J Clin Pathol 2002; 117 (Suppl): S95-103.

04. Maheshwari A, porter M, Shetty A et al. Womens awareness and perception of delay in child bearing. Fertility and Sterility 2008; 90:1036-42.
05. Infertility, Causes, diagnosis, risks and treatment. [cited 2015 March 21] Available from: http://www. medical news today.com/articles /165748.php

06. Gurunath S, Pandian Z, Anderson RA et al. "Defining infertility- A systematic review of prevalence studies". Human Reproduction Update 2011; 17 (5): 575-88.

07. Himmel W, Ittner E, Kochen MM et al. "Voluntary Childlessness and being Childfree". British Journal of General Practice 1997; 47 (415): 111-8.

08. Infertility treatment and research. [cited 2015 March 19] Available from : http://www.bims-bd.com/itrc.htm

09. "Adult and Youth Literacy, 1990-2015: Analysis of data for 41 selected countries UIS/2012/LIT/TD/0" (PDF). UNESCO Institute for Statistics. 2012. ISBN 978-92-9189$117-7$.

10. Hoem $J$ and Hoem B. The Impact of Female Employment on Second and Third Births in Modern Sweden. Stockholm Research Reports in Demography, University of Stockholm 1987; No. 36, 1-17.

11. Wright RE, Ermisch JF, Hinde PRA andJoshi HJ. The third birth in Great Britain. Journal of Biosocial Science 1988; 20, 489-96.

12. Rahman $\mathrm{M}$, Da Vanzo $\mathrm{J}$ and Razzaque $\mathrm{A}$. When will Bangladesh reach replacement fertility? The role of education and family planning services. In Expert Group Meeting on Completing the Fertility Transition, New York, 11-14th March 2002. Compiled by United Nations Department of Economic and Social Affairs, Population Division, New York, pp. 343-57.

13. Akther $\mathrm{R}$, Afroj $\mathrm{H}$, Sultana $\mathrm{S}$. Changes in the Practice of Contraceptive Prevalence - An Observational Study, Bangladesh Medical Journal 2008; 37(1): 10-4.

14. Wright J, Duchesne C, Sabourin S et al. Psychosocial distress and infertility: Men and women respond differently. Fertility Steril 1991; 55, 100-8.

15. Freeman EW, Rickels K, Tausig J et al. Emotional and psychosocial factors in follow-up of women after IVFET treatment. A pilot investigation. Acta Obstet Gynecol Scand 1987; 66, 517-21

16. Matsubayashi H, Hosaka $\mathrm{T}$ and Izumi S. Increased depression and anxiety in infertile Japanese women resulting from lack of husband's support and feelings of stress. General Hospital Psychiatry 2004; 26, 398-404.

17. Monga M, Alexandresc B and Katz SE. Impact of infertility on quality of life, marital adjustment and sexual function. Urology2004; 63, 126-30.

18. King RB. Sub fecundity and anxiety in a nationally representative sample. Social Medicine, 2003; 56,739-51.

19. Tan S, Duan $X$ and Tang $X$. The psychological effect of clinical examination on women with tubal infertility. Hua Xi Yi Ke Da Xue Xue Bao. 2001; 32, 254-6. 